\title{
Análisis de las estrategias de encuadre discursivo en la cobertura electoral sobre Vox en los titulares de la prensa española ${ }^{1}$
}

\section{Analysis of the discursive framing strategies in the electoral coverage of Vox in the headlines of the Spanish press}

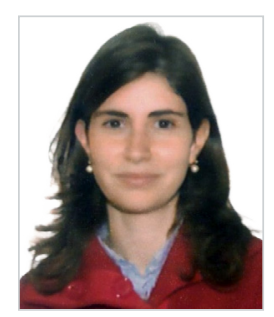

Ana Mancera Rueda. Profesora titular en el Departamento de Lengua Española, Lingüística y Teoría de la Literatura de la Universidad de Sevilla. Ha publicado seis monografías y más de una treintena de artículos sobre el estudio del español coloquial, las relaciones entre oralidad y escritura, la cortesía lingüística y el análisis del humor verbal en los medios de comunicación. Actualmente forma parte del Instituto Universitario de Estudios sobre América Latina y del grupo IHDEA, dedicado a la Investigación en Humanidades Digitales y Español de América, en el seno del cual desarrolla sus investigaciones centradas en el discurso mediado por ordenador, especialmente en las interacciones producidas a través de las redes sociales y en los diarios digitales. Asimismo, forma parte del equipo de investigación del proyecto PRODISNET-02: Procesos discursivos en internet: desplazamientos enunciativos y efectos hiperbólicos en el discurso político (Ref. RTI2018-093523-B-I00), financiado por el Ministerio de Ciencia, Innovación y Universidades.

Universidad de Sevilla, España anamancera@us.es

ORCID: 0000-0001-5343-4935

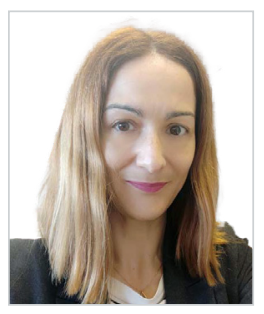

Paz Villar-Hernández. Doctora por la Universitat de València, Licenciada en Periodismo (Ciencias de la Información) por la Universitat Politècnica de València y Máster en Educación y TIC (Universitat Oberta de Catalunya). En la actualidad trabaja como técnico en el Servei de Formació Permanent i Innovació Educativa de la Universitat de València. Entre sus intereses de investigación están el discurso político, la comunicación audiovisual, los medios de comunicación, la edición científica y la Educación Superior. Es editora de la revista científica, Research in Education and Learning Innovation Archives (REALIA): https//www.uv.es/realia y forma parte de los Comités Editoriales de Journal of New Approaches of Educational Research (NAER) y RELIEVE (Revista Electrónica de Investigación y Evaluación Educativa) entre otros. Ha trabajado en Duke University (Estados Unidos) y ha realizado estancias en Northampton University y K.U. Leuven. Ha participado en los proyectos de investigación PRODISNET 01 y PRODISNET 02. Su índice H es 2 (diciembre 2019).

Universitat de València, España

viherma@uv.es

ORCID: 0000-0001-9617-1688

1 Esta contribución se inscribe en el marco del Proyecto de Investigación PRODISNET-02: Procesos discursivos en internet: desplazamientos enunciativos y efectos hiperbólicos en el discurso político (Ref. RTI2018-093523-B-I00), del Ministerio de Ciencia, Innovación y Universidades. Agradecemos los valiosos comentarios de dos evaluadores anónimos sobre una versión anterior de este trabajo.

Cómo citar este artículo:

Mancera Rueda, A.; Villar-Hernández, P. (2020). Análisis de las estrategias de encuadre discursivo en la cobertura electoral sobre Vox en los titulares de la prensa española. Doxa Comunicación, 31, pp. 315-340.

https://doi.org/10.31921/doxacom.n31a16 
Recibido: 30/06/2020 - Aceptado: 17/10/2020

\section{Resumen}

La presente investigación se basa en el análisis de un corpus de 413 titulares que encabezaron los textos informativos de ocho diarios españoles, durante la cobertura electoral sobre Vox, en el transcurso de los comicios generales celebrados en España en abril de 2019. Siguiendo el modelo desarrollado por Gallardo Paúls (2014; 2021 en prensa), que estudia las categorías pragmáticas de acuerdo con el nivel textual, el interactivo y el enunciativo, hemos podido identificar determinadas estrategias de encuadre discursivo que contribuyen a orientar cognitivamente los titulares de todos los periódicos que conforman nuestro corpus. Si bien la ilocutividad representativa fue la mayoritaria en los textos recopilados, un análisis pormenorizado revela el empleo por parte de algunos de estos medios -como ABCy La Vanguardia o El País y El Diario- de una estrategia léxica marcada (a través del empleo de metáforas, metonimias, nominalizaciones con valor irónico, etc.), capaz de suscitar preactivaciones contrarias a dicha formación política.

\section{Palabras clave:}

Encuadre; estrategias discursivas; periodismo político; prensa española; titulares.

\section{Introducción}

Desde la década de 1980, el populismo de derecha ha experimentado un crecimiento constante de votos en Europa (González Calleja, 2001; Bale, 2003; Mudde, 2007; Alonso y Rovira Kaltwasser, 2015), tanto en los comicios al Parlamento Europeo, como en las elecciones nacionales de los estados miembros (Redacción, 2019; TIMBRO, 2019). Esta tendencia no es tan solo europea, sino que parece formar parte de una dinámica global ${ }^{2}$.

Hasta el año 2019, España parecía constituir una excepción a dicha tendencia (González Enríquez, 2017), pero dejaría de serlo en las elecciones generales de abril de 2019, en las que el partido de extrema derecha Vox obtuvo 24 diputados; un resultado que afianzó en las elecciones celebradas pocos meses después, en noviembre de 2019, en las que consiguió 52 diputados, logrando así convertirse en la tercera fuerza política española.

Desde el final de la dictadura, la extrema derecha contó con un espacio político propio en partidos como Falange Española de las JONS, Falange Española (Auténtica), Falange Española Independiente, el Círculo Español de Amigos de Europa (CEDADE), el Frente Nacional, las Juntas Españolas o la coalición de Fuerza Nueva, que obtuvo un escaño en las elecciones generales de 1979. Sin embargo, a excepción de esas elecciones y de cierto éxito electoral del partido Plataforma per Catalunya $(\mathrm{PxC})$ en elecciones municipales y autonómicas de principios del siglo XX (2002, 2007 y 2011), su apoyo

2 Como demuestran los gobiernos de Donald Trump en Estados Unidos, Jair Bolsonaro en Brasil, Rodrigo Duterte en Filipinas, Recep Tayyip Erdogan en Turquía y Narendra Modi en la India. 
electoral apenas fue significativo hasta el año 2019. Como señala Ferreira (2019: 74), en España este espacio político de la ultraderecha estaba muy dividido y "ha presentado habitualmente un claro sesgo antidemocrático".

En 2019, la irrupción de Vox en las instituciones representativas parlamentarias cambió dicha tendencia. Pero Vox ya había hecho acto de presencia en la política nacional varios años antes, puesto su fundación data de 2013 y fue llevada a cabo por varios miembros del Partido Popular críticos con la gestión de Mariano Rajoy en materia económica y en relación con los nacionalismos periféricos, así como con los presuntos casos de corrupción en el seno de dicha formación política. Entre sus fundadores se encontraba Santiago Abascal, elegido presidente del partido en 2014. Vox es considerado como un representante más de la derecha radical europea, defensora del nacionalismo, el nativismo, el autoritarismo, el populismo, los valores tradicionales y el neoliberalismo. Como han puesto de manifiesto Acha (2019) y Oñate (2021), en tan solo siete años, Vox ha introducido en el discurso político español una agenda temática y unas estrategias comunicativas escasamente presentes hasta entonces en el contexto mediático nacional.

Sin embargo, la presencia de Vox en los medios de comunicación no ha sido continua. Según la base de datos Factiva, en 2014 -es decir, al año siguiente de su fundación-, los términos "Vox" o "Abascal" aparecieron solo en 180 ocasiones en los periódicos objeto de análisis en este trabajo, cifra que varía ligeramente hasta el año 2018, cuando aparece en 2.819 textos periodísticos. En este sentido, Olalla, Chueca Montuenga, y Moreno Torres (14/01/2019) señalan que, durante la campaña de las elecciones autonómicas andaluzas de diciembre de 2018, en las que Vox logró por primera vez representación en un parlamento autonómico, "recibió más atención en España que partidos con intención de voto similar (Pacma), y además obtuvo un nivel de cobertura excepcional en comparación con los principales partidos políticos”. Refiriéndose a esa misma cobertura mediática, Enguix Oliver y Gallardo Paúls (2020, en prensa) la califican como "desmedida para ser un partido sin presencia en las instituciones". Esto nos ha llevado a plantearnos si durante la campaña electoral de abril de 2019 se mantuvo esta misma tendencia.

El papel desempeñado por los medios de comunicación en el ascenso del populismo de derecha en Europa ha sido objeto de análisis en los últimos años (Walgrave y De Swert, 2004; Esser, Stepinska y Hopmann, 2016; Ekström y Morton, 2017; Doroshenko, 2018), si bien, a juicio de Esser et al. (2016), aún queda mucho trabajo por hacer. Son diversos los estudios que señalan la influencia que los medios de comunicación han tenido en el crecimiento de estos partidos (Wodak, 2015; Doroshenko, 2018; Murphy y Devine, 2018). Por ejemplo, la mayor cobertura periodística de determinados temas -como la inmigración o el nacionalismo-, el encuadre con el que se abordan y su asociación tradicional con algunos partidos es objeto de análisis del trabajo de Walgrave y De Swert (2004) sobre el ascenso del Vlaams Blok holandés. De acuerdo con Esser et al. (2016), tres son los patrones seguidos por el sistema mediático tradicional en relación a los movimientos populistas: (1) unos países han optado por ofrecer escasa cobertura, mientras esos partidos han tenido escasa representación parlamentaria y el cordón sanitario del resto de los partidos hacia esas formaciones así lo ha permitido; (2) otros han optado por una cobertura claramente negativa, lo que no ha evitado el ascenso de estos grupos políticos; o (3) se ha optado por ofrecer una cobertura crítica sin perder nunca de vista los daños que un discurso populista de este tipo podría conllevar para la salud democrática nacional. En relación al caso español, Enguix Oliver y Gallardo Paúls (2020, en prensa), al analizar la cobertura periodística sobre Vox durante las elecciones andaluzas de 2018, identificaron un predominio de los patrones (2) y (3). 


\section{Corpus y metodología}

El objeto de nuestra investigación es conocer cómo encuadró discursivamente la prensa española generalista de ámbito nacional la información que publicó sobre Vox durante la campaña de las elecciones generales del 28 de abril de 2019, unos comicios en los que por primera vez obtuvo representación parlamentaria en el Congreso de los Diputados.

La metodología de la que nos hemos servido es el análisis de discurso de base pragmática. El modelo de análisis utilizado es el desarrollado por Gallardo Paúls (2014; 2021 en prensa), que vincula los tres niveles lingüísticos descritos por Morris (1985) con los presupuestos de la lingüística cognitiva (Fillmore, 1976; Langacker, 1987; Lakoff, 1990). A las modalidades de encuadre discursivo presentadas por Gallardo Paúls (2014; 2021 en prensa), es decir, la enunciativa, la textual y la interactiva, incorporamos el análisis de algunos aspectos formales de la pieza periodística, que constituyen lo que denominamos encuadre "formal o externo" (Villar Hernández, 2015) [Tabla 2].

Los medios de comunicación objeto de estudio fueron seleccionados teniendo en cuenta los datos de audiencia de ComScore de marzo de 2019. En estos, El País, La Vanguardia, El Mundo y ABC encabezaban las audiencias de prensa en formato digital en ese mismo orden, seguidos de 20 Minutos, El Confidencial, El Español, El Diario y OK Diario. Todos estos medios fueron seleccionados para nuestra investigación, a excepción de 20 Minutos. La muestra quedó constituida por ocho periódicos, entre los que había cuatro cabeceras históricas -ABC, La Vanguardia, El País y El Mundo- y cuatro nativas digitales -El Confidencial, El Español, El Diario y OK Diario-. Los textos periodísticos fueron descargados en noviembre de 2019 de las ediciones digitales de los medios indexados en la base de datos Factiva (Dow Jones). Para la selección se emplearon como criterios de búsqueda los términos "Vox" y "Abascal", unidos por el buscador booleano "and", durante el período de campaña, es decir, del 12 al 26 de abril de 2019. Dado que Factiva no recopila las noticias publicadas en OK Diario, la búsqueda de estas se realizó en Google, empleando los mismos criterios y acotándola a la página web de este diario. Tras un proceso de revisión y criba, el corpus quedó conformado por 413 piezas informativas, según las siguientes frecuencias y porcentajes [Tabla 1]:

Tabla 1. Presencia de los términos "Vox" y "Abascal" en prensa durante la campaña electoral del 28A

\begin{tabular}{|l|c|c|}
\hline Periódicos & Frecuencia & $\%$ \\
\hline ABC & 29 & 7,0 \\
\hline EL CONFIDENCIAL & 25 & 6,1 \\
\hline EL DIARIO & 44 & 10,7 \\
\hline EL ESPAÑOL & 74 & 17,9 \\
\hline EL MUNDO & 42 & 10,2 \\
\hline EL PAÍS & 60 & 14,5 \\
\hline LA VANGUARDIA & 33 & 8,0 \\
\hline OK DIARIO & 106 & 25,7 \\
\hline Total & 413 & 100,0 \\
\hline
\end{tabular}

Fuente: Elaboración propia 
El análisis se llevó a cabo exclusivamente sobre el titular de esos textos informativos, elemento que en palabras de van Dijk (1990: 83) constituye: "La pieza fundamental de la noticia en la medida en que representa su macroestructura, es decir, el espacio en el que han de resumirse los aspectos más destacados de la noticia”. El titular periodístico no solo es un elemento esencial para capturar la atención del lector sino que, como apunta Mancera Rueda (2014), además de esta función apelativa posee una función identificativa y una función hipertextual, ya que en los diarios digitales el titular es, con frecuencia, el único elemento de acceso a la noticia. Este hecho acentúa todavía más su relevancia para el periodista, que sabe que de este ejercicio creativo depende su capacidad de atracción del lector y la consolidación de la audiencia. Para el análisis de los datos se creó una ficha en Microsoft Excel que recogía las siguientes categorías de análisis [Tabla 2]:

Tabla 2. Categorías de análisis empleadas en la investigación

\begin{tabular}{|c|c|}
\hline \multicolumn{2}{|c|}{ ENCUADRE EXTERNO O FORMAL } \\
\hline \multirow{8}{*}{ Periódico } & $A B C$ \\
\hline & El Confidencial \\
\hline & El Diario \\
\hline & El Español \\
\hline & El Mundo \\
\hline & El País \\
\hline & La Vanguardia \\
\hline & OKDiario \\
\hline Fecha de publicación & Desde el 12 hasta el 16 de abril de 2019 \\
\hline \multicolumn{2}{|l|}{ Titular } \\
\hline \multicolumn{2}{|l|}{ ENCUADRE TEXTUAL } \\
\hline \multicolumn{2}{|c|}{ Estrategia informativa: gestión temática } \\
\hline \multirow{4}{*}{ Temas } & Policy issues \\
\hline & Political issues \\
\hline & Campaign issues \\
\hline & Personal issues \\
\hline \multicolumn{2}{|l|}{ ENCUADRE INTERACTIVO } \\
\hline \multicolumn{2}{|c|}{ Estrategia intertextual: dialogismo } \\
\hline \multirow{2}{*}{ Intertextualidad } & Sí \\
\hline & No \\
\hline \multicolumn{2}{|l|}{ ENCUADRE ENUNCIATIVO } \\
\hline \multicolumn{2}{|l|}{ Estrategia léxica: designación } \\
\hline \multirow{2}{*}{ Estrategia léxica “marcada” } & Sí \\
\hline & No \\
\hline \multirow{2}{*}{ Rasgos de especial incidencia } & Relaciones léxicas \\
\hline & Inferencias \\
\hline
\end{tabular}




\begin{tabular}{|l|l|}
\hline \multirow{2}{*}{ Tipo de léxico } & Valorativo \\
\cline { 2 - 2 } & No valorativo \\
\hline \multirow{4}{*}{ Estrategia predicativa: actancialidad } & Vox \\
\cline { 2 - 2 } Actancialidad & Abascal \\
\cline { 2 - 2 } & Miembros, votantes o candidatos de Vox \\
\cline { 2 - 2 } & Otros \\
\hline \multirow{5}{*}{ Estrategia intencional: ilocutividad } & \\
\hline \multirow{5}{*}{ Ilocutividad } & Representativa \\
\cline { 2 - 2 } & Expresiva Positiva \\
\cline { 2 - 2 } & Expresiva Negativa \\
\cline { 2 - 2 } & Compromisoria \\
\cline { 2 - 2 } & Declarativa \\
\cline { 2 - 2 } & Directiva \\
\hline
\end{tabular}

Fuente: Elaboración propia

El análisis de los datos fue realizado por un codificador. Los resultados fueron estudiados con el paquete de análisis estadístico IBM SPSS versión 21 y se complementaron con un análisis cualitativo.

En un primer lugar se analizan diferentes estrategias de encuadre empleadas por cada una de las cabeceras en el nivel textual y en relación con los temas que fueron objeto de atención por parte de los distintos diarios; en segundo lugar, se identifican las estrategias de encuadre que se circunscriben al nivel interactivo, para dilucidar por medio de qué mecanismos lingüísticos se produce la transmisión de aseveraciones ajenas por parte del sujeto reproductor; y, en último lugar, las empleadas en el nivel enunciativo en lo que concierne a la intención comunicativa del emisor (ilocutividad), el agente de la acción y la localización de elementos léxicos que pueden llegar a condicionar la interpretación de los lectores.

\section{Análisis y resultados}

\subsection{La estrategia de encuadre en el nivel textual}

Para la identificación del encuadre textual, es decir, para conocer la agenda temática en torno a este partido propuesta por los medios objeto de estudio, vamos a focalizar nuestro análisis en la identificación de los principales temas sobre los que versan los titulares que conforman el corpus, basándonos en la clasificación de Patterson (1980) tal y como la recoge Mazzoleni (2010), que distingue entre policy issues, political issues, campaign issues y personal issues. En esta tipología, bajo el marbete policy issues se incluyen las propuestas programáticas de los partidos referidas a cada una de las áreas de la política: educación, economía, salud, inmigración, justicia, interior, etc.; los political issues hacen referencia a la ideología del partido, alianzas electorales, pactos previos o posteriores, cambios en las estructuras de los partidos, etc., en general, cuestiones relativas a la relación entre distintos partidos y dentro del propio partido; los campaign issues tienen 
que ver con todo lo relativo a ese período preelectoral, desde la preparación de las candidaturas, hasta la organización y participación en debates, mítines, o cualquier otro evento, así como los pronósticos electorales. Finalmente, los personal issues remiten a la esfera íntima y personal del líder y otros candidatos, además de a su cualificación profesional y política, o a la relación del candidato con su partido.

Como puede apreciarse en el siguiente gráfico [Imagen 1], los campaign issues son los que cuentan con una representación mayor en los titulares analizados -superior al 70 \%-, dado el contexto en el que fueron publicados:

Clasificación temática de los titulares de acuerdo con cada publicación

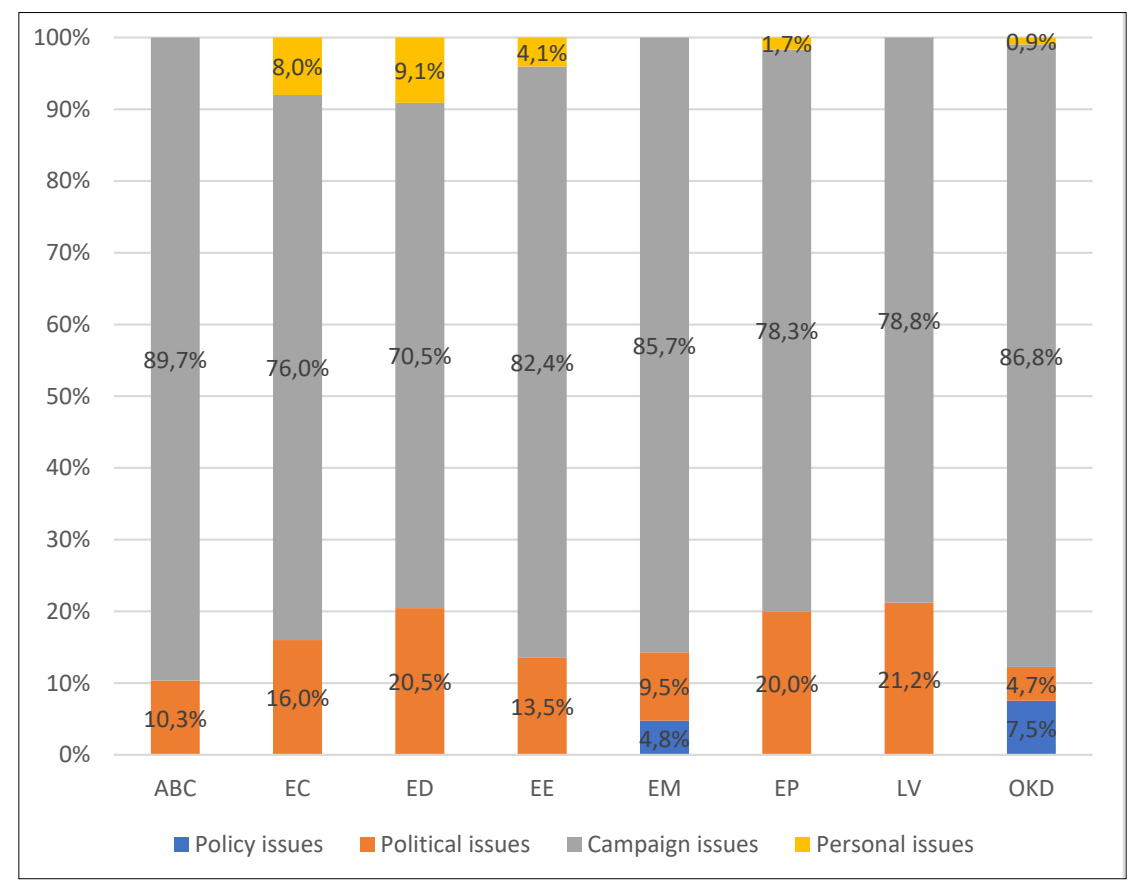

Fuente: Elaboración propia

Por ejemplo, los diarios informan sobre los sucesos que tuvieron lugar durante la campaña electoral,

[Ej. 1.] Grupos radicales hostigan los mítines de Vox en el País Vasco (El País, 13/04/2019).

[Ej. 2.] Atacan de madrugada la sede nacional de Vox (La Vanguardia, 25/04/2019).

las decisiones de la Junta Electoral Central,

[Ej. 3.] La Junta Electoral veta a Vox para el debate, pero permite a Junqueras hacer campaña $(A B C, 17 / 04 / 2019)$. 
los integrantes de las listas electorales,

[Ej. 4.] Henríquez de Luna, exconcejal del PP con Esperanza Aguirre, se pasa a Vox (El Confidencial, 21/04/2019)

o las predicciones de voto de los sondeos,

[Ej. 5.] Vox supera a Cs y PSOE en el Ayuntamiento de Madrid (El Mundo, 15/04/2019).

e incluso dan a conocer los precios a los que se cotizan los apoyos a las principales formaciones políticas en las casas de apuestas, para ayudar "a vislumbrar tendencias", como se afirma en la siguiente noticia:

[Ej. 6.] Las apuestas dan las mismas opciones a Sánchez y Casado... y Abascal queda tercero (El Confidencial, 24/04/2019).

El segundo lugar lo ocupan los titulares que versan sobre political issues, denominación que en la categorización de Patterson (1980) hace referencia a aquellos textos sobre la ideología de los partidos políticos,

[Ej. 7.] Los boicots a los actos de PP, Cs y Vox unen a la derecha frente a Sánchez reaccionario (El País, 15/04/2019).

las alianzas y afinidades entre diversas formaciones,

[Ej. 8.] Vox se une a Podemos para rechazar una iniciativa del Partido Popular a favor de la Tauromaquia $(A B C, 12 / 04 / 2019)$.

[Ej. 9.] Marine Le Pen: “Por Vox sentimos mucha amistad, es un partido ineludible” (El Español, 20/04/2019).

o las relaciones de estas con la sociedad civil. Numerosos titulares se hicieron eco de la decisión de Vox de prohibir el acceso a sus mítines de periodistas que trabajaban para determinados medios de comunicación, pero adviértase la distinta selección léxica escogida por cada diario para informar sobre esta cuestión:

[Ej. 10.] Vox continúa con sus expulsiones a periodistas tras el veto a El Español (El Español, 18/04/2019).

[Ej. 11.] Vox hace una purga de periodistas en el único canal en el que aportan información del partido (El Diario, 18/04/2019).

[Ej. 12.] Informar sobre Vox entre insultos, vetos y amenazas: "Sois una vergüenza, nos tendréis siempre enfrente" (El Diario, 25/04/2019).

[Ej. 13.] Elecciones 2019: Santiago Abascal desconoce el veto a periodistas en actos de Vox pero respalda a su equipo de comunicación (OK Diario, 24/04/2019).

Así, en el [Ej. 10], El Español opta por un verbo durativo y la autorreferencia para presentar al propio medio de comunicación como experimentador de la acción de Vox, pero poniendo de manifiesto al mismo tiempo que no han sido los únicos periodistas afectados por la decisión de esta formación política de impedirles la cobertura de sus actos de campaña; en el titular mostrado en [Ej. 11], el sujeto también es Vox, pero El Diario escoge una locución verbal -"hacer una purga"-marcada con un valor axiológico más negativo; en cambio, en el del [Ej. 12] se opta por un infinitivo y el foco ya no se pone en la prohibición del partido, sino en la dificultad de la actividad profesional desempeñada por los comunicadores, aunque en este caso se evita la referencia al propio medio, a pesar de que, como puede leerse en el cuerpo de la noticia, los "insultos, vetos y amenazas" a los que se alude-un ejemplo de los cuales se presenta en el enunciado en discurso directo- han sido dirigidos también contra El Diario; en el titular de El País mostrado en el [Ej. 13] también se opta por una locución 
verbal marcada con un valor axiológico negativo, pues se trata de un uso metafórico de carácter bélico; sin embargo, a diferencia de los otros titulares, el de OK Diario evita cualquier tipo de crítica hacia Vox.

Como puede apreciarse en el gráfico precedente [Imagen 1], La Vanguardia y El Diario son los periódicos que más political issues recogen, ya que en ellos este tipo de titulares cuenta con una representatividad del $21,2 \%$ y del 20,5\%, respectivamente. En cambio, en OK Diario estos representan únicamente el 4,7\%.

Por otra parte, algunos medios informan también sobre personal issues, como puede apreciarse en el siguiente texto, en el que se alude a una acción circunscrita a la práctica religiosa de un individuo:

[Ej. 14.] El número dos de Vox por Barcelona asistió a una misa en honor a Franco que terminó con el 'Cara al sol' (El Diario, 17-04-2019).

La omisión de la referencia deíctica temporal podría inducir al lector a pensar que se trata de una información de actualidad cuando, en realidad, la eucaristía a la que se hace alusión tuvo lugar en 2016, es decir, tres años antes de la publicación de la noticia. Tal vez con esta información carente de actualidad noticiosa se trate de otorgar una mayor fuerza argumentativa a la línea editorial de El Diario -muy crítica con la ideología de este partido-al poner de relieve las filiaciones de los candidatos de Vox con el franquismo. Según muestra la [Imagen 1], este periódico es el que más titulares sobre personal issues contiene -un 9,1 \%-, seguido de El Confidencial -un 8,0\%-, medio en el que podemos encontrar noticias como la siguiente, que opta por dar cuenta de las manifestaciones de afecto hacia el líder de este partido difundidas en Instagram por parte de su esposa, recurriendo a diversos adjetivos calificativos:

[Ej. 15.] La felicitación más cariñosa y personal a Santi Abascal por su 43 cumpleaños (El Confidencial, 15/04/2019).

La relevancia noticiosa de este tipo de informaciones en el transcurso de una campaña electoral podría ser cuestionable, de ahí posiblemente que otros medios como ABC, El Mundo o La Vanguardia hayan optado por no recoger contenidos correspondientes a la esfera privada de los representantes de esta formación política.

Por último, bajo el marbete de policy issues, Patterson (1980) incluye las referencias a medidas políticas concretas vinculadas, por ejemplo, con el ámbito económico, el social o el territorial. Sobre tales temas destacan los titulares de los periódicos OK Diario y El Mundo -aunque con una representatividad muy reducida, del 7,5\% y del 4,8 \%, respectivamente, quizás por el carácter especializado de este tipo de informaciones-, que tratan cuestiones relacionadas con la economía y la fiscalidad desde una perspectiva que favorece a Vox y que, en ocasiones, choca con la buena praxis periodística, como muestran los siguientes ejemplos:

[Ej. 16.] Vox: El sistema fiscal español desperdicia hasta 1.15 euros por cada euro que invierte (OK Diario, 14/04/2019).

[Ej. 17.] Las medidas económicas en los primeros 100 días con Vox en la Junta de Andalucía (OK Diario, 26/04/2019).

Llama la atención cómo en el primero de los titulares recogidos supra el diario parece hacerse eco de una de las propuestas programáticas de Vox, pero sin identificarla específicamente como un enunciado de discurso referido. Por otra parte, con el siguiente texto, de estructura nominal, se da cuenta de un análisis llevado a cabo por el propio periódico acerca de la política económica desarrollada por la Junta de Andalucía, comunidad autónoma en la que gobierna el Partido Popular en coalición con Ciudadanos, y con el apoyo externo de Vox. Sin embargo, véase cómo en el titular únicamente se hace 
mención a ese último partido -a pesar de que este no dirige ninguna de las consejerías del gobierno andaluz- y se omite capciosamente la referencia a las otras dos formaciones.

\subsection{La estrategia de encuadre en el nivel interactivo}

El análisis del nivel interactivo pretende conocer las fórmulas de incorporación del receptor en el discurso empleadas. En este epígrafe estudiaremos, en primer lugar, aquellos mecanismos lingüísticos determinados por la consideración del enunciatario al que se dirige el mensaje para centrarnos, a continuación, en el estudio del dialogismo y de las distintas formas de reproducir el discurso ajeno.

Por ejemplo, algunos de los titulares de nuestro corpus se presentan como apelaciones directas al lector:

[Ej. 18.] VOX: Vea la entrevista completa de Eduardo Inda a Santiago Abascal (OK Diario, 15/04/2019).

De acuerdo con Hernando Cuadrado (1988: 87), el imperativo de los verbos de percepción sensorial comporta con frecuencia un estímulo para el oyente, "por integrarlo plenamente en el diálogo". Algo ya puesto de manifiesto por Narbona Jiménez, para quien

ciertas formas verbales apelativas (sobre todo de verbos referentes a la esfera de los sentidos) no son sólo elementos fáticos, sino que cumplen también un claro papel de señal demarcativa de inicio de estructura (1986 [1989: 187]).

Una función que podría atribuirse también al presente del subjuntivo "vea" en el [Ej. 18], con el que OK Diario formula una suerte de intervención iniciativa para instar a los internautas a acceder a la entrevista publicada por el propio medio de comunicación. En cambio, en otros titulares se adopta la modalidad interrogativa, quizás en un intento de representar las cuestiones que pueden plantearse los ciudadanos:

[Ej. 19.]¿Puede ir Vox a algún debate electoral? ¿habrá debate en Atresmedia? (El País, 17/04/2019).

De acuerdo con Charaudeau (2012: 31), el discurso periodístico "presenta una instancia de información, una instancia de público (ella constituye también su propia instancia de mediación) y tiene una finalidad discursiva de hacer saber a propósito de acontecimientos del mundo". De ahí que en los titulares publicados en las ediciones digitales de los diarios resulten cada día más numerosos los ejemplos en los que se hace uso del adverbio modal así, que contrae una relación de deixis textual con el cuerpo de la noticia, y que puede entenderse como una invitación al lector para "incitarle a saber" accediendo al hipervínculo que le dirigirá a la información publicada en el periódico:

[Ej. 20.] Así cerró su polémica empresa de numismática Rubén Pulido, el número 2 de Vox por Sevilla (El Español, 11/04/2019).

A veces, entre el titular y la fotografía que lo acompaña se produce una relación de contigüidad o ampliación (Mancera Rueda, 2019). Como ha puesto de manifiesto Duque Gómez (2016: 23), este tipo de relaciones de discurso "presentan sus miembros como conectados en el orden natural de las cosas. No hay discontinuidad entre ellos y la operación perceptiva

3 Como ha puesto de manifiesto Garrido Medina (1999: 3904): “Al emplear los tipos de oración interrogativa e imperativa, hay una distribución obligatoria de información, quedando siempre explícita la de que el hablante presenta como deseable una acción, o como desconocida una información. [...] Las interrogativas piden tener en cuenta los conocimientos del hablante y del oyente al respecto, tal como los calcula el hablante". 
que proponen es una progresión espacial o temporal". Por ejemplo, adviértase la referencia exofórica ad oculos (Bühler, 1934 [1979]) del demostrativo en el siguiente titular,

[Ej. 21.] Cuatro años separan estas dos fotos de Santiago Abascal en Sevilla (OK Diario, 25/04/2019).

Imagen publicada por OK Diario para ilustrar el titular “Cuatro años separan estas dos fotos de Santiago Abascal en Sevilla”

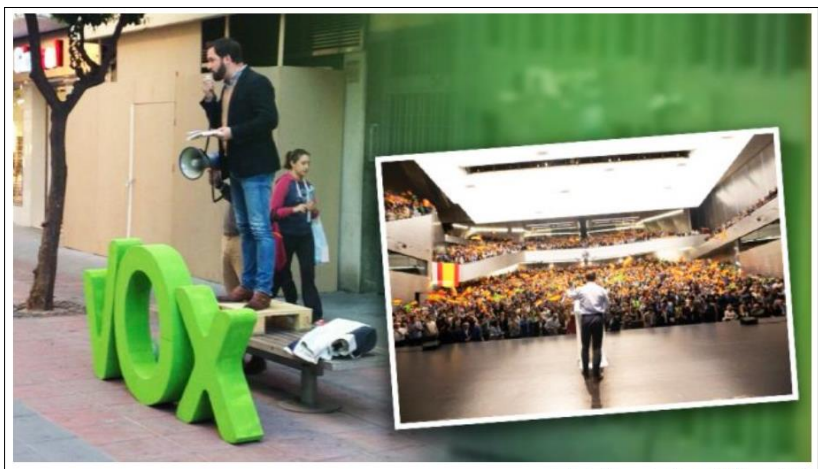

Fuente: OK Diario. Imagen disponible en: <https://okdiario.com/espana/cuatro-anos-separan-estas-dos-fotos-abascal-sevilla-4034877> . Última consulta: 14/06/2020

o del sintagma nominal del [Ej. 22], al que el adjetivo calificativo le otorga un carácter valorativo y, podría decirse que el titular cumple una finalidad descriptiva ${ }^{4}$ :

[Ej. 22.] El divertido tuit-resumen de Abascal sobre el debate de TVE (OK Diario, 22/04/2019).

Fotografía de un tuit de Santiago Abascal publicada por OKDiario

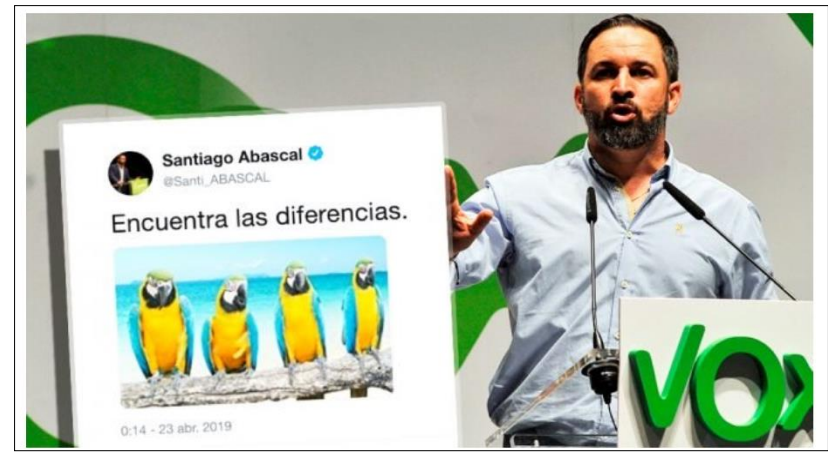

Fuente: OK Diario. Imagen disponible en:<https://okdiario.com/espana/divertido-tuit-resumen-abascal-sobre-debate-tve-4018915>. Última consulta: 14/06/2020

4 No en vano, según Duque Gómez (2016: 23), "las relaciones de contigüidad espacial son propias de la descripción, cuando tratan entidades concretas". 
El principio de predictibilidad subyace también, según Gallardo Paúls (2021 en prensa), en la configuración de algunas de las estrategias de encuadre interactivo. Sin embargo, resulta frecuente que en los textos de nuestro corpus se persiga una ruptura de las expectativas del lector, en aras de un fin dramatizante de captación:

[Ej. 23.] Errejón, el crítico de 'Juego de Tronos’ para El Español: “Vox metería a Daenerys en casa para fregar” (El Español, 23/04/2019).

Véase asimismo cómo con los enunciados suspendidos de estos titulares, El Confidencial parece querer otorgar realce informativo a unos datos que pueden sorprender a su audiencia,

[Ej. 24.] Las apuestas dan las mismas opciones a Sánchez y Casado... y Abascal queda tercero (El Confidencial, 24/04/2019)

[Ej. 25.] El mundo empresarial cree que el PSOE ganará las elecciones... y Vox supera a Cs (El Confidencial, 22/04/2019).

algo a lo que contribuyen, asimismo, los parentéticos de los siguientes titulares:

[Ej. 26.] Los moros que 'liberaron’ Covadonga en 1937 (que Vox y Abascal prefieren ignorar) (El Confidencial, 21/04/2019).

[Ej. 27.] Vox es el partido que genera más entusiasmo en redes (y sin hacer publicidad) (El País, 25/04/2019).

En el primero de ellos, El Confidencial se sirve del parentético para poner de manifiesto su actitud disociativa hacia la postura ideológica adoptada por Vox. También El País se sirve de un parentético que introduce un enunciado aclaratorio, pero cabría plantearse si su propósito es meramente el de ponderar este logro alcanzado por el partido de Santiago Abascal o si cabe ver en tal tipo de titulares una estrategia de este medio de comunicación para advertir a sus lectores sobre el ascenso en la intención de voto hacia la extrema derecha, algo a lo que podrían contribuir también estos otros textos, en los que se recurre al dialogismo:

[Ej. 28.] La prensa internacional alerta del posible auge de Vox y de la inestabilidad política tras el 28-A (El País, 25/04/2019).

[Ej. 29.] Sánchez alerta de la influencia de Vox y rechaza concesiones al secesionismo (El País, 23/04/2019).

El dialogismo es otra de las estrategias que Gallardo Paúls (2021, en prensa) identifica dentro del encuadre interactivo. El discurso periodístico constituye una obliqua allocutio, un decir indirecto, "un género textual básicamente integrado por formas diferentes de reproducir o referir el discurso ajeno" (Méndez García de Paredes, 1999: 101). De acuerdo con esta autora, la función del periodista, como locutor y productor textual, no es solo informar sobre un determinado hecho novedoso, sino evocar la situación comunicativa en la que el enunciador transmitió la noticia. El locutor, al incorporar el discurso ajeno en el propio discurso lo asume sintácticamente, pero lo atribuye de forma explícita a su enunciador. No obstante, como puede apreciarse en el siguiente gráfico [Imagen 4], la mayor parte de los titulares de nuestro corpus no contiene ningún enunciado de discurso referido: 
Representatividad de los enunciados de discurso referido en los titulares de cada diario

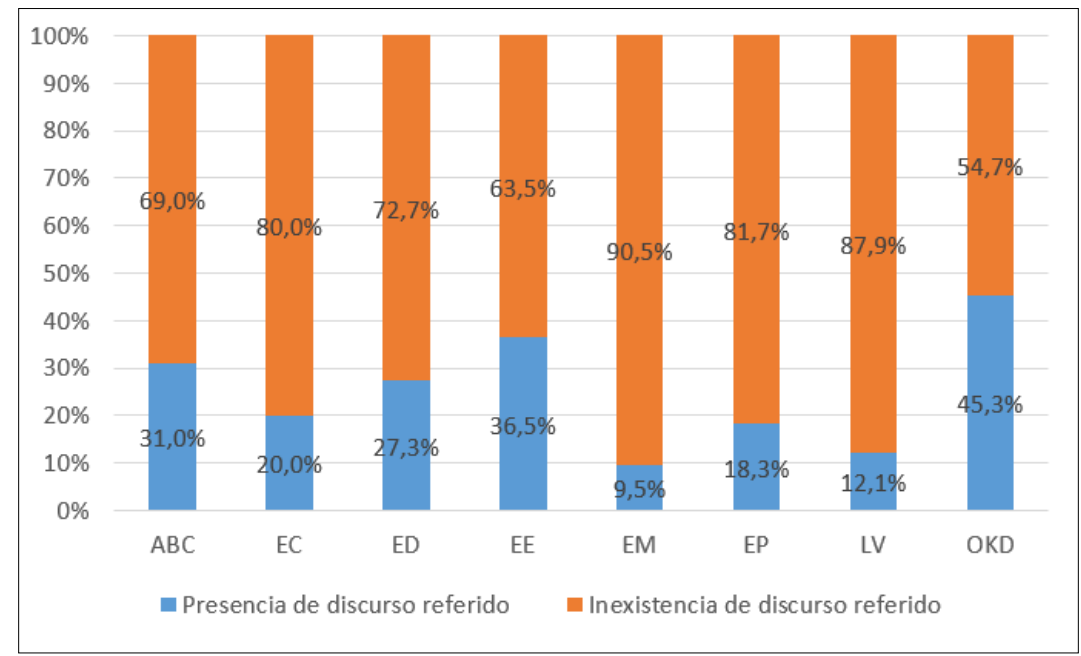

Fuente: elaboración propia

OK Diario, El Español y $A B C$ son los medios que más se sirven de este tipo de enunciados, si bien no de manera mayoritaria, pues su representatividad es del 45,3\%, el 36,5\% y el 31,0\%, respectivamente. En el caso de OK Diario, resulta llamativo el elevado número de titulares de carácter declarativo en los que se difunden las afirmaciones del líder de Vox; recogemos a continuación una pequeña muestra de ellos, para no alargar en exceso la longitud de este trabajo:

[Ej. 30.] Santiago Abascal: "El 28 de abril nos jugamos la unidad de España y la libertad de los españoles" (OK Diario, 15/04/2019).

[Ej. 31.] Santiago Abascal: "Me comprometo a investigar la compra del chalé de Pablo Iglesias" (OK Diario, 15/04/2019).

[Ej. 32.] Santiago Abascal: "El Rey está hasta la corona de la clase política” (OK Diario, 15/04/2019).

Este periódico parece actuar incluso como portavoz de los gustos y opiniones de Santiago Abascal en cuestiones ajenas a la política:

[Ej. 33.] Santiago Abascal explica por qué no siente simpatía por el Athletic y critica su "política etnicista" de fichajes (OK

Diario, 13/04/2019).

Como ha puesto de manifiesto Reyes (1984: 206), el uso del discurso directo en los textos periodísticos "constituye una cautela epistemológica fruto del carácter impersonal con el que se retransmiten los discursos ajenos en los géneros informativos". De ahí que en algunos de los titulares que hemos analizado, el periodista se limite a identificar el sujeto enunciador como fuente de las declaraciones que reproduce:

[Ej. 34.] Santiago Abascal: "Pero cuántas casas demoscópicas van a cerrar el 29 de abril” (El Confidencial, 22/04/2019). 
Como "citador social", el periodista es "responsable de la reformulación del discurso ajeno, pero no de la veracidad de las afirmaciones que se recogen en la cita" (Mancera Rueda, 2009: 40). No obstante, en varios de los parágrafos reproductores (Girón Alconchel, 1985) recogidos en nuestro corpus, es posible identificar enunciados en estilo directo que no parecen haber sufrido reformulación alguna ${ }^{5}$, ya que contienen disfemismos y términos característicos de la modalidad de uso coloquial, tal vez con objeto de "retratar" a los candidatos de Vox mostrando su particular idiolecto:

[Ej. 35.] Vox y la Reconquista en las elecciones: "Don Pelayo era un tío con dos huevos" (El Confidencial, 12/04/2019).

[Ej. 36.] Abascal pide que la Policía pueda echar okupas “de una patada en el culo” sin proceso judicial (El Español, 25/04/2019).

El verbo de comunicación es, de las señales demarcativas de la cita (Girón, 1985), el que mejor refleja el encuadre discursivo que el periodista otorga a los actos de habla que reproduce. Y es que, según Maldonado González (1999: 3559), muchos verba dicendi "incluyen una información que condiciona directamente la manera en que el receptor interpretará el discurso citado e imponen, por tanto, una cierta lectura al destinatario". Por ejemplo, en el siguiente titular, se confiere al acto de habla recogido a continuación en estilo directo la fuerza ilocutiva de una advertencia, aunque llama la atención que estas declaraciones se atribuyan al partido, sin identificar al sujeto de la enunciación reproducida ${ }^{6}$ :

[Ej. 37.] Vox advierte a Juanma Moreno: "A partir de ahora ya no hay plazo de cortesía” (OK Diario, 24/04/2019).

El verbo advertir puede adquirir una orientación ilocutiva de amenaza, "cuando el lector de periódicos pone los discursos referidos por el periodista en relación con contextos que se suponen conflictivos, de forma que las consecuencias de lo dicho se valoran negativamente por el destinatario" (Méndez García de Paredes, 2001: 365). Y en este otro llama la atención tanto el uso de un verbo de valoración negativa (Maldonado González, 1999: 3562) como el del adjetivo calificativo traidor, antepuesto a las siglas del partido que dirige el Gobierno Vasco:

[Ej. 38.] Abascal acusa al "traidor" PNV de la violencia contra Vox: "Nos han dejado a merced de los perros rabiosos" ( $E l$ Español, 14/04/2019).

Tal adjetivo, al aparecer entrecomillado, puede ser interpretado fácilmente por el lector como una muestra de heterogeneidad discursiva, si bien hasta el penúltimo párrafo de la noticia ${ }^{7}$ no se atribuye específicamente al líder de Vox:

[Ej. 39.] El líder de la formación verde [...] defendió que España "está mucho más viva de lo que piensan sus enemigos”. Entre ellos, Abascal citó, de nuevo, al PNV y a Pedro Sánchez, a quien acusó de apoyarse en los nacionalistas vascos, que son "el partido más traidor" de todos, en su opinión (El Español, 14/04/2019).

5 Contrariamente a lo que suele hacerse en las declaraciones publicadas en la prensa, para ajustarlas a los criterios de corrección imperantes en la mayor parte de los medios, como ya demostramos en Mancera Rueda (2009).

6 Para conocerlo, el lector tendrá que acceder al hipervínculo que contiene la noticia completa, en la que sí se informa de que estas palabras fueron formuladas por Alejandro Hernández, portavoz de Vox en el Parlamento de Andalucía, en el transcurso de una rueda de prensa sobre las medidas pactadas con el PP para el gobierno de dicha comunidad autónoma.

7 Alcoba Rueda (1999: 94-95) explica la formación de los titulares del enunciado periodístico “como el resultado, primero, de un proceso de topicalización [...] de un segmento de la noticia; y luego, de una operación consiguiente y obligatoria de anteposición [...] que da origen al segmento titular, relacionado con el segmento noticia a la que antecede por distintas manifestaciones de una relación anafórica o polar con un segmento determinado de la noticia”. 
Asimismo, otro de los procedimientos de reproducción del discurso ajeno presente en los diarios analizados es el de la cita implícita, que se caracteriza por que el enunciado de discurso referido carece de atribución explícita a un sujeto concreto. Constituye por tanto una muestra de heterogeneidad discursiva, un alejamiento enunciativo del periodista que declina su responsabilidad ilocutiva en una parte de su discurso, lo que le permite mostrar su actitud irónica o su postura crítica, como cabría pensar ante la lectura del siguiente titular:

[Ej. 40.] Vox y su "falsa" y “manipulada" idea de la Reconquista (El País, 12/04/2019).

Los adjetivos calificativos del [Ej. 40] aparecen entrecomillados, de ahí que pueda inferirse que se trata de una cita, pero no se especifica la fuente de la que proceden. Podría decirse que este titular, publicado a primera hora del 12 de abril de 2019 en la portada digital de El País, responde también a un propósito de captación para atraer la atención de los lectores del diario, con el fin de que accedan al hipervínculo de la noticia. Solo de esta forma podrían conocer que tales valoraciones hacia la postura ideológica de Vox no fueron formuladas por el propio diario, sino por "historiadores expertos en la Edad Media", como se asegura en el subtítulo:

[Ej. 41.] Historiadores expertos en la Edad Media aseguran que el término nunca se usó durante aquel periodo y que alude a una visión errónea y anacrónica de la historia (El País, 12/04/2019).

Quizás por cautela epistemológica, en la edición de las 14:53 h. se opta por incluir en el titular una referencia a su fuente como señal demarcativa de la cita ${ }^{8}$, si bien esta no resulta demasiado específica:

[Ej. 42.] La idea de la Reconquista que cuenta Vox es “falsa” y “manipulada”, según los expertos (El País, 12/04/2019).

\subsection{La estrategia de encuadre en el nivel enunciativo}

Por último, tres son los principales aspectos que Gallardo Paúls (2021, en prensa) identifica en el análisis del encuadre enunciativo, elementos con los que se pretende descubrir la intención comunicativa presente en estos titulares: el acto de habla ilocutivo -que concierne al tipo de acción que el emisor pretende realizar por medio de su mensaje-, el acto de habla proposicional -manifestado en la selección léxica- y la actancialidad -vinculada con el reparto de la acción y su responsabilidad en el ámbito extraverbal-.

En la [Imagen 5] presentamos los resultados cuantitativos del análisis de la ilocutividad en los textos que conforman nuestro corpus:

8 En Mancera Rueda y Villar Hernández (2021, en prensa) realizamos un análisis más detallado sobre el dialogismo presente en este tipo de textos, algo que las limitaciones de este trabajo nos impiden realizar aquí. 
Tipos de ilocutividad presente en los distintos diarios

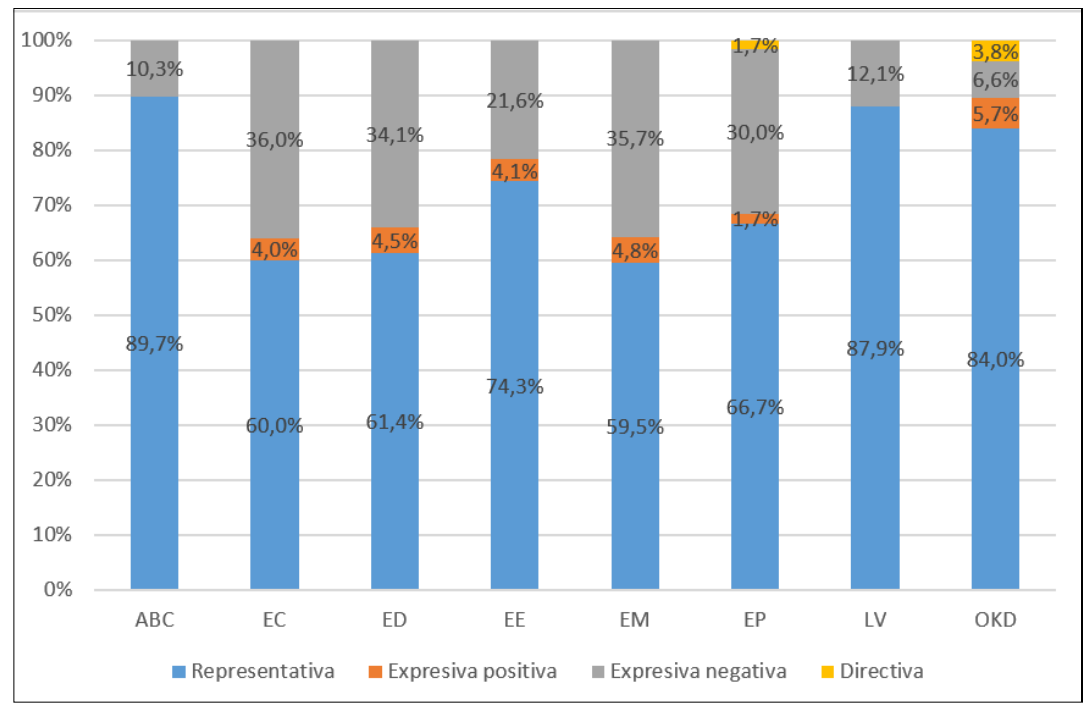

Fuente: elaboración propia

En todos los diarios analizados advertimos un claro predominio de los titulares de ilocutividad representativa -con unos porcentajes entre el 89,7 \% y el 59,5 \%-, al manifestar informaciones dotándolas de valor veritativo:

[Ej. 43.] El juez deja en libertad a los cuatro detenidos en los incidentes tras el mitin de Vox ayer en Bilbao (El Diario, $14 / 04 / 2019$ )

[Ej. 44.] Vox recaba 50.000 firmas para avalar su lista europea (El País, 22/04/2019).

Incluso, en algunos casos, se llega a atribuir tal valor a lo que en realidad constituyen meras predicciones y ni siquiera se hace mención de la fuente de la que estas proceden:

[Ej. 45.] Abascal da el «sorpasso» a Podemos y se posiciona cerca de ser amenaza de Cs $(A B C, 20 / 04 / 2019)$.

Por ejemplo, hasta el segundo párrafo de la noticia no es posible saber que la afirmación recogida en el titular precedente constituye una especulación sobre las intenciones de voto de los ciudadanos españoles, a partir de un sondeo llevado a cabo para $A B C$ por la empresa demoscópica GAD3, el 16 de abril de 2019.

A veces se hace ostensible tal valor veritativo, como en el siguiente titular, en el que El Confidencial se sirve de la modalidad epistémica para "publicitar" una exclusiva, destacando el grado de certeza de la proposición contenida en su enunciado y, al mismo tiempo, rebatiendo implícitamente uno de los argumentos esgrimidos por Pedro Sánchez durante el debate electoral celebrado la noche anterior:

[Ej. 46.] La verdad tras la carta de violencia de género: ni es de Vox ni se han dado datos (El Confidencial, 24/04/2019). 
En el transcurso del debate, el candidato socialista había mostrado una carta en la que, supuestamente, la Junta de Andalucía solicitaba sus datos a un trabajador de las unidades de violencia de género de Sevilla. Esta fue exhibida por Pedro Sánchez como prueba de que el gobierno de dicha comunidad autónoma -en manos del Partido Popular y de Ciudadanos, como ya hemos explicado- cumplía órdenes de Vox, puesto que en febrero de 2019 el partido de Santiago Abascal puso en duda la profesionalidad de los miembros de las unidades de violencia de género, alegando que se trataba de "chiringuitos ideologizados" y, a través de la Mesa del Parlamento de Andalucía, solicitó que se hicieran públicos los datos de sus trabajadores. Sin embargo, el titular de El Confidencial anuncia una investigación llevada a cabo por el propio diario, en la que se pone en duda la veracidad de tal argumentación. De acuerdo con Enguix Oliver y Gallardo Paúls (2020, en prensa):

La estrategia intencional de predominio representativo se asocia sobre todo a la estrategia estructural de los géneros de información (noticias, reportajes, crónicas), mientras la de predominio expresivo corresponde más frecuentemente a los géneros de opinión (columnas y editoriales).

No obstante, aunque los titulares de nuestro corpus corresponden exclusivamente a textos pertenecientes a géneros informativos, hemos podido localizar en ellos numerosos ejemplos en los que predomina la expresividad negativa. Especialmente en El Confidencial y El Mundo, donde estos cuentan con una representatividad del 36,0 \% y del 35,7 \%, respectivamente:

[Ej. 47.] Vox tira la toalla en Facebook: por qué es el único partido que ya no paga por anunciarse (El Confidencial, 23/04/2019).

[Ej. 48.] Lío en la derecha: el voto 1+1+1 en el Senado; La difusión de mensajes que piden la división del voto entre PP, Cs y Vox genera dudas en los votantes (El Mundo, 25/04/2019).

De acuerdo con la Real Academia Española (2014), tirar la toalla significa “darse por vencido, desistir de un empeño", por lo tanto, en este titular puede advertirse la preeminencia de la modalidad axiológica, pues El Confidencial recurre a dicha locución verbal de carácter coloquial para formular una evaluación negativa acerca de la estrategia de campaña adoptada por Vox en la red social Facebook. Tal polaridad puede atribuirse también al sintagma nominal -"lío en la derecha"-, con el que El Mundo sintetiza valorativamente la información que presenta a continuación. A estos dos medios se unen $E l$ Diario y El País, con porcentajes elevados de expresividad negativa - 34,1 \% y 30 \%, respectivamente-

La expresividad positiva se manifiesta especialmente en OK Diario-con una representatividad del 5,7 \%-, donde se publicaron titulares como estos en los que el sufijo aumentativo y el adjetivo "total" aportan un valor intensificador a la información sobre la gran afluencia de público a los mítines de Vox:

[Ej. 49.] Llenazo de Santiago Abascal en Albacete: "VOX no llama a la izquierda o a la derecha, sino a España entera" ( $O K$ Diario, 20/04/2019).

[Ej. 50.] Elecciones 2019: Llenazo total de VOX en Las Rozas: 5000 simpatizantes arropan a Abascal (OK Diario, 23/04/2019).

También este periódico es el que más recurre a la ilocutividad directiva -en un 3,8 \% de los ejemplos- para apelar a sus lectores, planteándoles preguntas, e incluso instándoles a seguir a través del propio medio de comunicación los actos propagandísticos del partido de Santiago Abascal: 
[Ej. 51.]¿Qué cambiará en la Economía si gobierna el bloque PP-Ciudadanos-Vox tras el 28A? (OK Diario, 26/04/2019).

[Ej. 52.] Siga en OK Diario el discurso de Abascal con el que ha contraprogramado el debate (OKDiario, 23/04/2019).

Las muestras de ilocutividad expresiva se manifiestan en los diarios analizados por medio de lo que podría calificarse como una "estrategia léxica marcada", especialmente en el caso de El Mundo-66,7 \%-, El Confidencial-56,0 \%- y El Español-52,7 \%- [Imagen 6]:

Existencia o no de una estrategia léxica marcada

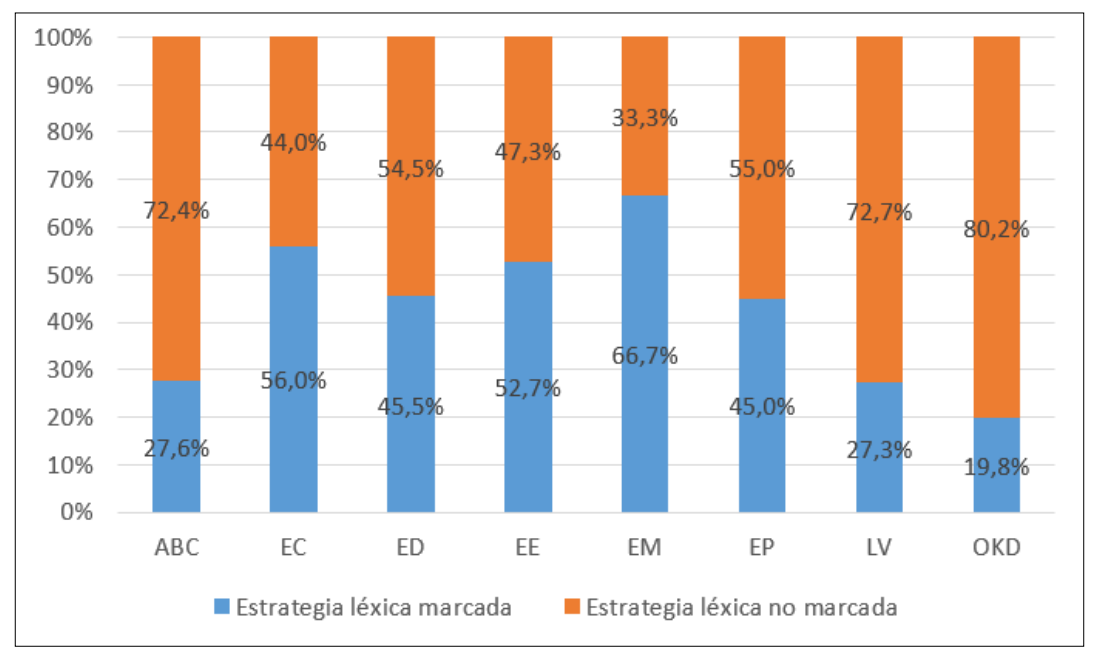

Fuente: elaboración propia

Por ejemplo, a esta estrategia parece responder el uso recurrente de metáforas vinculadas con el campo semántico de la seducción ${ }^{9} \mathrm{o}$ con el ámbito bélico ${ }^{10}$ :

[Ej. 53.] Vox corteja a Henríquez de Luna para sus listas (El Mundo, 17/04/2019).

[Ej. 54.] Las armas de Carlos Herrera para superar a la Cadena Ser: Vox y la radicalización política (El Español, 19/04/2019).

[Ej. 55.] De Lezo a Covadonga: las gestas marcan la campaña de Vox ( $A B C, 13 / 04 / 2019)$.

las metonimias,

[Ej. 56.] Ortega Smith y Monasterio, caras de Vox en Ayuntamiento y Comunidad (ABC, 19/04/2019).

9 En Garrido Medina (2013) puede encontrarse un interesante análisis sobre metáforas de distinto tipo, entre las que se encuentran las que vinculan al sexo con la política.

10 Como ha puesto de manifiesto Llamas Saíz (2010), la metáfora conceptual UNA DISCUSIÓN ES UNA GUERRA (Lakoff y Johnson, 1980: 77) resulta muy recurrente en la noticia periodística. 
y las nominalizaciones ${ }^{11}$ como la de este titular, en el que se ironiza acerca del "estado placentero de exaltación emocional y admirativa” (Real Academia Española, 2014), supuestamente alcanzado por el líder de Vox al pronunciar su primer mitin de campaña durante una visita al santuario de Covadonga:

[Ej. 57.] Abascal, éxtasis ante Don Pelayo (La Vanguardia, 12/04/2019).

Como ya pusimos de manifiesto en Mancera Rueda (2014), abundan en la prensa española los titulares con este tipo de estructura bimembre, en los que el periodista se sirve del signo ortográfico de la coma para reflejar la pausa oral del lector y asimilarla al verbo copulativo elidido. Pero en nuestro corpus es posible localizar también estructuras unimembres como la siguiente, que consta exclusivamente de un sintagma nominal modificado por un sintagma preposicional:

[Ej. 58.] Hartazgo en dirección a Vox y el PSOE (El Mundo, 15/04/2019).

El titular mostrado en el [Ej. 58] constituye también una muestra de lo que comentábamos anteriormente acerca de otorgar valor veritativo a una mera predicción extraída de un sondeo. En él, el juicio negativo que el sustantivo "hartazgo" implica podría entenderse como reflejo de la actitud crítica de los potenciales electores hacia las dos formaciones políticas que se mencionan en el titular. Sin embargo, la lectura de la noticia revela que, en realidad, esta pretende informar sobre cómo el descontento de la población de Ceuta y Melilla con la gestión del PP -que gobernaba en ambos territorios desde hacía 18 y 19 años, respectivamente- podría canalizarse en el incremento de votos para Vox y el PSOE en ambos territorios, no en toda España, como se da a entender. Quizás la ambigüedad de este titular hizo que, pocas horas después, fuera sustituido en la edición digital por este otro, en el que se abandona la estructura nominal:

[Ej. 59.] El hartazgo se transforma en votos para Vox y PSOE en Ceuta y Melilla (El Mundo, 15/04/2019).

Asimismo, en los titulares de nuestro corpus resulta frecuente la preactivación de significados implícitos a través de inferencias que solo los lectores al tanto de la actualidad noticiosa serán capaces de interpretar cabalmente, como se refleja en los siguientes textos:

[Ej. 60.] El tridente de Vox: sigue caminando solo en mujer, inmigración y memoria histórica (El Confidencial, 14/04/2019).

[Ej. 61.] Las colas de Vox no llegan a las librerías: Dragó y Abascal venden menos que Sánchez (El Confidencial, 15/04/2019).

En el [Ej. 60] se alude a las propuestas defendidas por Vox en el Parlamento de Andalucía, que no obtuvieron ningún tipo de apoyo por parte del resto de los partidos. Por otra parte, en el [Ej. 61] se hace alusión a la biografía de Santiago Abascal -redactada por Fernando Sánchez Dragó, de ahí la referencia a este escritor en el titular- y a la de Pedro Sánchez, estableciendo una comparación entre ambas en cuanto al número de ejemplares vendidos y, al mismo tiempo, poniendo de manifiesto que la afluencia de público a los actos de campaña organizados por Vox no contó con un reflejo en la asistencia a las librerías para adquirir la semblanza de su líder.

11 La tendencia nominalizadora del titular periodístico fue puesta ya de manifiesto por Steel (1971: 13), para quien "el grupo nominal adquiere [en este tipo de textos] una relevancia y una extensión mayor que en otros estilos de lengua”, o por Casado Velarde (1978: 103), capaz de advertir cómo “con gran frecuencia en los titulares se presenta de forma nominalizadora el hecho que se expresa con un verbo en el cuerpo de la noticia". 
El tercero de los elementos que Gallardo Paúls (2021, en prensa) identifica como manifestación del encuadre enunciativo es la actancialidad. A pesar de que a la hora de configurar nuestro corpus hemos seleccionado únicamente los titulares que contienen, al menos, una referencia a Vox o a su líder, nos ha resultado significativa la constatación de que en la mayor parte de ellos los miembros de esta formación política no son agentes de los actos que se refieren, como puede apreciarse en la [Imagen 7]:

\section{Distribución de la actancialidad en relación con Vox}

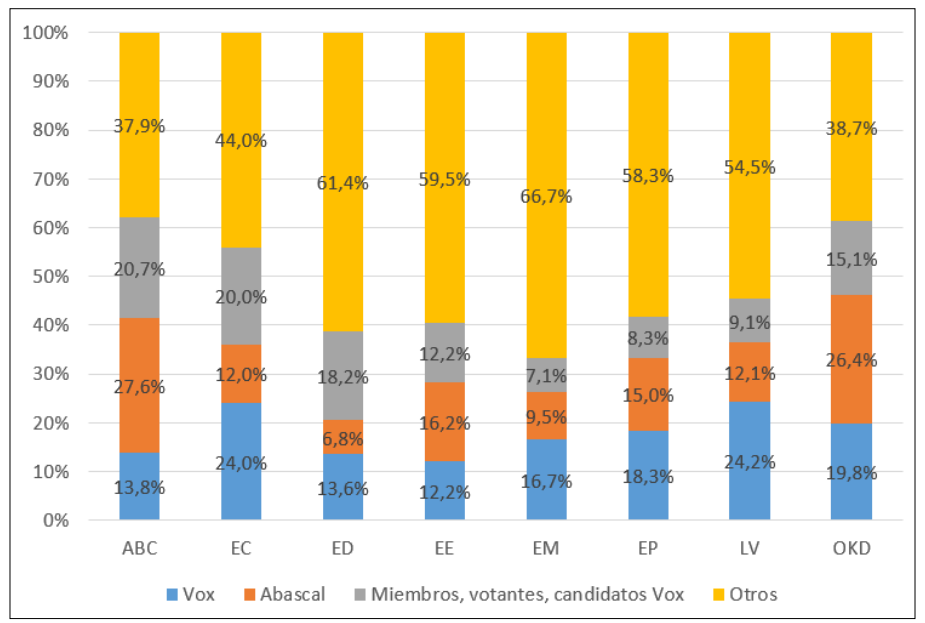

Fuente: elaboración propia

Esto resulta especialmente ostensible en los textos que hemos extraído de El Mundo y de El Diario, en los que la actancialidad recae en políticos y agentes sociales ajenos a Vox -en un 66, 7 \% y en un 61,4 \% de los casos, respectivamente-, como puede observarse en los siguientes ejemplos:

[Ej. 62.] Sánchez da aire a Vox para visualizar a "las tres derechas" (El Mundo, 12/04/2019).

[Ej. 63.] La Junta desbarata el debate que quería Sánchez con Vox (El Mundo, 17/04/2019).

En el [Ej. 62] se da cuenta de la estrategia adoptada por el líder del PSOE al acceder a tomar parte en un debate en el que también participaba el candidato de Vox, algo finalmente impedido por la Junta Electoral Central, ya que la intervención de la formación de Abascal en este acto contravenía la normativa española, que exige que todas las televisiones respeten la proporcionalidad obtenida en las elecciones precedentes, y la presencia de Vox en él suponía un agravio respecto a otros partidos que contaban con mayor representación nacional y, en cambio, no habían sido invitados a intervenir en el "debate a cinco" organizado por Atresmedia, como se refleja en el [Ej. 63].

La actuación de la Junta Electoral Central fue motivada por un recurso presentado por el equipo jurídico de Carles Puigdemont, de ahí que el ex presidente de la Generalidad de Cataluña se presente como actante en el siguiente titular: 
[Ej. 64.] Puigdemont saca ${ }^{12}$ a Vox del debate de Atresmedia gracias a la jurisprudencia de 2015 (El Diario, 16/04/2019).

Algunos medios recogen las valoraciones de otros partidos acerca de la estrategia electoral adoptada por Vox, como muestran estos titulares de $A B C$ y El Confidencial:

[Ej. 65.] El PP cree que los debates dejarán fuera de juego a Abascal ( $A B C, 20 / 04 / 2019)$.

[Ej. 66.] Elecciones generales: Narbona alerta de que la política de Vox ya “se siente” en Andalucía (El Confidencial, 25/04/2019).

Llegando incluso a hacerse eco de las advertencias sobre el ascenso de esta fuerza política; así, en el [Ej. 66], el actante que formula el acto de habla es Cristina Narbona, presidenta del Partido Socialista.

Además, con frecuencia, la referencia a Vox suele aparecer junto con las menciones de los otros dos grandes partidos pertenecientes al espectro político de la derecha, a los que se hace referencia mediante el sintagma nominal "el bloque de derechas" o "la derecha del tridente", equiparando y homogeneizando de esta forma a este partido de derecha radical bajo el marbete de "la derecha", y conformando una especie de sinécdoque que favorece su imagen pública:

[Ej. 67.] Zapatero advierte del voto al bloque de derechas: “Lo de Vox se contagia” (OK Diario, 26/04/2019).

[Ej. 68.] La ministra Dolores Delgado contra PP, Ciudadanos y Vox: "Votar a la derecha del tridente es llevar a España a la penumbra" (OK Diario, 13/04/2019).

\section{Conclusiones}

En 1925 el Dr. Glenn Frank, rector de la Universidad de Wisconsin y editor jefe de The Century Magazine ${ }^{13}$, puso de manifiesto la influencia de los titulares periodísticos en la configuración de la opinión pública, con las siguientes palabras: "When you stop to think how few people read beyond the headlines and how much of public opinion is made by headlines, you begin to realize the enormous influence exerted by the journalist who sits at a desk and writes the headlines"14. Dos años después, Emig (1927) llevó a cabo una encuesta con una muestra de 375 personas, que le permitió demostrar que la mayoría de los lectores de periódico norteamericanos forjaban su opinión basándose exclusivamente en la lectura de los titulares de noticias. Décadas más tarde, van Dijk (1983: 78) alertó también sobre cómo los valores e ideologías de los periodistas y de los periódicos se reflejan en este tipo de textos a menudo "de una manera sutil", llegando a condicionar "la manera como los lectores entenderán, memorizarán y usarán la información de la noticia para la elaboración de su conocimiento y opiniones acerca de la 'realidad'”.

Según han puesto de manifiesto Gallardo Paúls y Enguix Oliver (2014: 97): “[L]os periodistas españoles, frente a sus colegas del norte y centro de Europa, tienden a mantener unas relaciones más simbióticas que competitivas con los políticos

12 El verbo sacar podría englobarse entre los denominados verba omnibus, al tratarse de una proforma poco limitada semánticamente. Por lo tanto, nos encontramos aquí ante un rasgo léxico característico de la presencia de la modalidad de uso coloquial en los titulares periodísticos. Para un estudio acerca de esta cuestión más detallado del que podemos realizar aquí cfr. Mancera Rueda (2014).

13 Una publicación periódica neoyorquina que alcanzó gran difusión durante el siglo XIX y las primeras décadas del XX.

14 Cit. en Emig (1927). 
parlamentarios, y [...] su actitud es en general más partidista y parcial”. Esto puede constatarse en los titulares de los textos informativos que conforman nuestro corpus, muchos de ellos redactados siguiendo los marcos lingüístico-cognitivos propuestos por las instancias políticas (Charaudeau, 2012) y las agendas temáticas fijadas por los partidos. Así, como hemos podido demostrar, las noticias más recurrentes en la cobertura electoral de Vox durante los comicios de abril de 2019 fueron las que daban cuenta de campaign issues sobre los actos electorales protagonizados por esta formación, sus candidatos o los sondeos acerca de la intención de voto a este partido. Esta cobertura fue significativa, pues en el corto período de campaña, tanto Vox como su líder aparecieron hasta en 413 titulares informativos.

El estudio cuantitativo de los titulares sobre Vox o su líder publicados en géneros informativos de ocho diarios españoles durante dicha campaña ha revelado cómo dos medios digitales -OK Diario y El Español- ofrecieron la cobertura más extensa sobre tal formación, principalmente el primero donde esa atención ocupó más del 25\% del total (25.7\%). Los periodistas de $O K$ Diario se sirvieron fundamentalmente del dialogismo, como estrategia de encuadre interactivo, para publicar titulares de carácter declarativo que otorgaban difusión a las afirmaciones de Santiago Abascal. También los de El Español hicieron uso de un buen número de enunciados de discurso referido, pero introducidos por verba dicendi que ponían de manifiesto su postura crítica hacia los representantes de un partido que, de acuerdo con las informaciones del propio diario, les había "vetado", impidiendo su presencia en los mítines y otros actos de campaña. Incluso la selección de determinados enunciados reproducidos en estilo directo, en los que los candidatos de Vox hacían uso de disfemismos, podría interpretarse como una estrategia de encuadre llevada a cabo por el periódico de Pedro J. Ramírez y también por El Confidencial, para desprestigiarlos. Al igual que señalaban Enguix Oliver y Gallardo Paúls (2020, en prensa) respecto a las elecciones andaluzas de 2018, en estas elecciones podríamos decir que el tipo de cobertura ofrecida mayoritariamente por la prensa española durante la campaña del 28A se adecuó a los modelos 2 y 3 identificados por Esser et al. (2016), es decir, que se realizó una cobertura fundamentalmente crítica sobre los actos de campaña organizados por Vox y las declaraciones de sus representantes.

De acuerdo con los resultados de nuestra investigación, las referencias a Vox fueron constantes en medios con diferentes sensibilidades políticas -bien a la izquierda o a la derecha del espectro político-, mayoritariamente a la hora de informar sobre temas vinculados con los propios comicios electorales campaign issues-; es decir que, pese a su escasa representación política en esos momentos, logró una considerable visibilidad en los diarios a lo largo de todo el período analizado.

Por otra parte, hemos constatado que los periódicos objeto de estudio encuadraron su discurso sobre Vox enunciando mayoritariamente asuntos relativos a la campaña, es decir, sobre la estrategia política de esta formación política en lo que respecta a la organización de los actos electorales, los eventos en los que tomaban parte o en los que eran vetados, etc., temas al fin y al cabo secundarios y alejados del debate sobre el compromiso político propiamente dicho (es decir, de los policy issues). De hecho, solo dos medios -OK Diario y El Mundo- trataron de forma significativa temas relacionados con su programa o su posicionamiento político.

La presencia mayoritaria de ese tipo de temas de campaña y, en segundo lugar, de los political issues -es decir, de cuestiones relativas a los sondeos, la participación ciudadana, los programas electorales, las coaliciones, cuestiones internas del partido, etc. - nos permite apuntar que, en este caso, se ha producido una mediatización de la política, en el sentido 
expuesto por Mazzoleni y Schutz (1999). Como ha puesto de manifiesto Casero Ripollés (2012: 23), tal mediatización provoca que sean los propios medios de comunicación los que regulen "la visibilidad social de los acontecimientos y los problemas públicos que afectan al conjunto de una sociedad", favoreciendo o bien el debate político de ideas y el compromiso cívico, o bien el predominio de asuntos banales, el conflicto político, el escándalo, y el espectáculo de la política. Esto último parece haber ocurrido en el periodo electoral analizado, en relación a Vox. Una línea de estudio futuro será conocer cómo evoluciona la cobertura informativa sobre este partido en los próximos comicios.

Por último, aunque en los ocho medios analizados existe un claro predominio de la ilocutividad representativa, en algunas noticias difundidas por $A B C$ y $E l M u n d o$ se atribuye valor veritativo a lo que en realidad no constituyen más que meras predicciones sobre la intención de voto de los ciudadanos respecto a Vox. Además, contrariamente a lo que cabría esperar en textos pertenecientes al género informativo, también podemos encontrar en este tipo de titulares numerosas muestras de expresividad negativa puesta de manifiesto por medio de lo que hemos identificado como una estrategia léxica marcada. Así, a pesar de defender una línea editorial muy diferente, ABC y La Vanguardia o El País y El Diario recurren a metáforas de carácter bélico, metonimias y nominalizaciones con valor irónico o términos axiológicos capaces de provocar preactivaciones contrarias a este partido, en la mente del lector al tanto de la actualidad noticiosa. Tales estrategias se encuadran en el nivel enunciativo, al igual que la actancialidad, que en la mayor parte de los textos de nuestro corpus se hace recaer no en los representantes de Vox, sino en otros políticos y agentes sociales que, por ejemplo, advierten sobre las consecuencias negativas que podrían derivarse del ascenso de esta formación política. Como hemos podido comprobar, tanto los periódicos "tradicionales" como las cabeceras "nativas digitales" hacen uso de similares estrategias de encuadre a la hora de redactar sus titulares, ya sea ante un ordenador, o sobre un escritorio, y es que las prácticas periodísticas descritas por el Dr. Glenn Frank en 1925 quizás no hayan cambiado excesivamente...

\section{Referencias bibliográficas}

Acha, B. (2019). No, no es un partido (neo)fascista. Agenda Pública. http://agendapublica.elpais.com/ no-no-es-un-partido-neofascista/

Alcoba Rueda, S. (1999). Titulación y relación de 'causalidad' en el enunciado informativo de la lengua periodística. En J. Garrido Medina (coord.). La lengua y los medios de comunicación: actas del Congreso Internacional celebrado en la Universidad Complutense de Madrid en 1996, vol. 1, 91-107.

Alonso, S. y Rovira Kaltwasser, C. (2015). Spain: No Country for the Populist Radical Right? South European Society and Politics, 20(1), 21-45. http://dx.doi.org/10.1080/13608746.2014.985448

Bale, T. (2003). Cinderella and her ugly sisters: the mainstream and extreme right in Europe's bipolarising party systems. West European Politics, 26(3), 67-90. http://dx.doi.org/10.1080/01402380312331280598

Bühler, K. (1934 [1979]). Teoría del lenguaje. Madrid: Alianza.

Casado Velarde, M. (1978). La transformación nominal, un rasgo de estilo de la lengua periodística. Cuadernos de Investigación Filológica, 4, 101-112. 
Casero-Ripollés, A. (2012). El periodismo político en España: algunas características definitorias. En A. Casero-Ripollés (ed). Periodismo político en España: concepciones, tensiones y elecciones, 19-46. La Laguna (Tenerife): Sociedad Latina de Comunicación Social. http://hdl.handle.net/10234/80553

Charaudeau, P. (2012). Los géneros: una perspectiva socio-comunicativa. En M. Shiro, P. Charaudeau y L. Granato (eds.). Los géneros discursivos desde múltiples perspectivas: teorías y análisis. Madrid/Frankfurt, Iberoamericana/Vervuert, 19-44.

Doroshenko, L. (2018). Far-Right Parties in the European Union and Media Populism: A Comparative Analysis of 10 Countries During European Parliament Elections. International Journal of Communication (12). https://ijoc.org/index. $\mathrm{php} / \mathrm{ijoc} / \mathrm{article} / \mathrm{view} / 7757 / 2422$

Duque Gómez, E. (2016). Las relaciones de discurso. Madrid: Arco/Libros.

Ekström, M. y Morton, A. (2017). The performances of right-wing populism: Populist discourse, embodied styles and forms of news reporting. En M. Ekström y J. Firmstone (Eds.), The Mediated Politics of Europe: A Comparative Study of Discourse, 289-316. Cham: Palgrave Macmillan.

Emig, E. (1927). The connotation of Newspaper Headlines. Journalism Quarterly, 4, 53-59.

Enguix Oliver, S. y Gallardo Paúls, B. (2020, en prensa). Coverage of the far-right in the Spanish written press: the case of Vox. En J. Santaemilia, Fuster-Márquez, Miguel, C. Gregori-Signes, y P. Rodríguez-Abruñeiras (Eds.). Exploring discourse and ideology through corpora. Berna: Peter Lang.

Esser, F, Stepinska, A. y Hopmann, D. N. (2016). Populism and the Media. Cross-National Findings and Perspectives. En T. Aalberg, F. Esser, C. Reinemann, J. Strömbäck, y C. d. Vrees (Eds.), Populist Political Communication in Europe, 365-380. London: Routledge.

Ferreira, C. (2019). Vox como representante de la derecha radical en España: un estudio sobre su ideología. Revista Española de Ciencia Política (51), 73-98. https://doi.org/10.21308/recp.51.03

Fillmore, C. (1976). Frame Semantics and The Nature of Language. Annals of the New York Academy of Sciences, 280, 20-32. Gallardo Paúls, B. (2014). Usos políticos del lenguaje. Un discurso paradójico. Madrid: Anthropos.

Gallardo Paúls, B. (2021, en prensa). El hablar como intención comunicativa. En O. Loureda y A. E. Schrott (Eds.), Manual de Lingüística del Texto. Berlin: De Gruyter.

Gallardo Paúls, B. y Enguix Oliver, S. (2014). "Estrategias de encuadre discursivo en periodismo político: análisis de un corpus de titulares”, Círculo de Lingüística Aplicada a la Comunicación, 58, pp. 90-109. Disponible en: < https://revistas. ucm.es/index.php/CLAC/article/view/45471>. Última consulta: 24-06-2020.

Garrido Medina, J. (1999). Los actos de habla. Las oraciones imperativas. En I. Bosque y V. Demonte (dirs.). Gramática descriptiva de la lengua española, vol. 3. Madrid: Espasa-Calpe, 3879-3928.

Garrido Medina, J. (2013). From epistemic neurolinguistics to metaphor in discourse. Cuadernos de Filología Francesa, 24, 227-246. 
Girón Alconchel, J. L. (1985). La 'escritura del habla' y el discurso indirecto libre en español. AFA, vol. XXXVI-XXXVII, 172-204.

González Calleja, E. (2001). Extrema derecha y fascismo en España y en Europa: elementos para un debate. Presentación. Hispania, LXI (207), 9-16. https://doi.org/10.3989/hispania.2001.v61.i207.305

González Enríquez, C. (08/06/2017). La excepción española: el fracaso de los grupos de derecha populista pese al paro, la desigualdad y la inmigración. Recuperado de: http://www.realinstitutoelcano.org/wps/wcm/connect/155407f2773a-4f08-ad08-aff2df759fdb/DT7-2017-GonzalezEnriquez-Excepcion-espanola-fracaso-grupos-derecha-populista. pdf?MOD=AJPERES\&CACHEID=155407f2-773a-4f08-ad08-aff2df759fdb

Hernando Cuadrado, L. A. (1988). El español coloquial en «El Jarama». Madrid: Playor.

Lakoff, G. (1990). Women, fire, and dangerous things: what categories reveal about the mind. Chicago IL etc.: University of Chicago Press.

Lakoff, G. y M. Johnson (1980). Metaphors we live by. Chicago: University of Chicago Press.

Langacker, R. W. (1987). Foundations of cognitive grammar. Stanford CA: Stanford University Press.

Llamas Saíz, C. (2010). Interpretación del discurso ajeno: la anáfora conceptual metafórica en la noticia periodística. Revista de investigación lingüistica, 13, 107-126.

Maldonado González, C. (1999). Discurso directo y discurso indirecto. En I. Bosque y V. Demonte (dirs.). Gramática Descriptiva de la Lengua Española, vol. 3. Madrid: Espasa-Calpe, 3549-3595.

Mancera Rueda, A. (2009). El discurso referido en teletipos y noticias de la prensa española. Círculo de lingüística aplicada a la comunicación, 40, 33-61, disponible en: <https://recyt.fecyt.es/index.php/CLAC/article/view/8122>. Última consulta: $10 / 06 / 2020$.

Mancera Rueda, A. (2014). Rasgos de carácter coloquial en los titulares de las noticias periodísticas en Internet. Pragmalingüística, 22, 78-97. Disponible en: < https://revistas.uca.es/index.php/pragma/article/view/1885>. Última consulta: 10/06/2020.

Mancera Rueda, A. (2019). Estrategias discursivas utilizadas por los periódicos españoles para atraer a lectores digitales. En D. Pons Olivé (ed.), El español de Cataluña en los medios de comunicación, Madrid/Frankfurt, Iberoamericana/ Vervuert, 37-62.

Mancera Rueda, A. y Villar Hernández, P. (2021, en prensa). 'Con Vox y voto': estrategias de encuadre discursivo en la cobertura mediática sobre la extrema derecha en España. En Retóricas negativas: la desinformación de derecha radical y su cobertura mediática, editado por Villar Hernández, Paz. Valencia: Tirant Humanidades.

Mazzoleni, G. (2010). La comunicación política. Madrid: Alianza Editorial

Mazzoleni, G. y Schulz, W. (1999). Mediatization of Politics: A Challenge for Democracy? Political Communication, 16 (3), 247-61. https://doi.org/10.1080/105846099198613

Morris, C. (1985). Fundamentos de la teoría de los signos. Barcelona: Paidós. 
Mudde, C. (2007). Populist Radical Right Parties in Europe. Cambridge: Cambridge University Press.

Murphy, J., y Devine, D. (2018). Does Media Coverage Drive Public Support for UKIP or Does Public Support for UKIP Drive Media Coverage? British Journal of Political Science, 50(3), 893-910. https://doi.org/10.1017/S0007123418000145

Méndez García de Paredes, E. (1999). Análisis de la reproducción del discurso ajeno en los textos periodísticos. Pragmalingüística, vol.7, 99-128.

Méndez García de Paredes, E. (2001). Aspectos gramaticales y discursivos de los verbos de comunicación. En E. Méndez, J. Mendoza y Y. Congosto (eds.). Indagaciones sobre la lengua: estudios de filología y lingüística españolas en memoria de Emilio Alarcos. Sevilla: Secretariado de Publicaciones de la Universidad de Sevilla, 349-370.

Narbona Jiménez, A. (1986 [1989]). "Problemas de sintaxis coloquial andaluza", RSEL, 16, 1986, pp. 229276 (recogido posteriormente en Sintaxis española: nuevos y viejos enfoques, Barcelona, Ariel, 1989, pp. 171203).

Olalla, S., Chueca Montuenga, E., y Moreno-Torres, J. P. (14/01/2019). ¿Cómo cubrieron a VOX los medios tradicionales? AgendaPública-ElPaís.Recuperadode:http://agendapublica.elpais.com/como-cubrieron-vox-los-medios-tradicionales/ Oñate, P. (2021, en prensa). El populismo y los partidos de derecha radical populista: caracterización, evolución y efectos. En P. Villar Hernández (ed.). Retóricas negativas: la desinformación de derecha radical y su cobertura mediática, València: Tirant Lo Blanch, 14-40.

Patterson, T. E. (1980). The mass media election: How americans choose their president. Nueva York: Praeger.

Real Academia Española (2014). Diccionario de la lengua española, 23. ${ }^{\mathrm{a}}$ ed., [versión 23.3 en línea]. Disponible en: <https:// dle.rae.es>. Última consulta: 10/06/2020.

Redacción (30/04/2019). Extrema derecha: quiénes son los líderes que están detrás del auge del populismo y el nacionalismo en Europa. BBC News Mundo. Recuperado de: https://www.bbc.com/mundo/noticias-internacional-47989567

Reyes, G. (1984). Polifonía textual. La citación en el relato literario. Madrid: Gredos.

Steel, B. (1971). Los estilos funcionales y la enseñanza del idioma. Español actual, 18, 9-18.

TIMBRO (2019). Timbro Authoritarian Populism Index. https://populismindex.com/wp-content/uploads/2019/02/ TAP2019C.pdf

van Dijk, T. A. (1983). Estructuras textuales de las noticias de prensa. Análisi. Quaderns de comunicació i cultura, 7/8, 77-105.

van Dijk, T. A. (1990). La noticia como discurso. Comprensión, estructura y producción de la información. Barcelona: Paidós. Villar Hernández, P. (2015). Análisis del discurso sobre la universidad en prensa durante el período 2010-2013: Universidad y discurso mediático. (PhD.). Universitat de València, Valencia. Recuperado de: http://roderic.uv.es/handle/10550/50571

Walgrave, S. y De Swert, K. (2004). The Making of the (Issues of the) Vlaams Blok. Political Communication, 21(4), 479-500. https://doi.org/10.1080/10584600490522743

Wodak, R. (2015). The Politics of Fear. What Right-Wing Populist Discourses Mean. Los Angeles / London / New Delhi / Singapore / Washington DC: SAGE. 